\title{
Utilization of Adonis aestivalis as a Dietary Pigment Source for Rainbow Trout Salmo gairdneri
}

\author{
Tadashi Kamata, ${ }^{* 1,2}$ Gavril Neamtu, ${ }^{* 3}$ Yoshito Tanaka, ${ }^{* 4}$ \\ Muneo Sameshima, ${ }^{* 4}$ and Kenneth L. Simpson*1 \\ (Received November 6, 1989)
}

\begin{abstract}
The flower, Adonis aestivalis and its pigment extract were fed to two different sizes of rainbow trout Salmo gairdneri at a level of $10 \mathrm{mg}$ total pigment $/ 100 \mathrm{~g}$ diest.

The larger fish (average weitht $400 \mathrm{~g}$ ) were fed the pigment extract for 8 weeks. In the males, carotenoids were mainly deposited in the skin and a samll amount was found in the flesh. However, in the females, a relatively high level of carotenoids was detected in the flesh.

The smaller fish were fed the diets containing Adonis flower petals or its pigment extract. After two weeks of feeding, the Adonis flower group discontinued feeding activity and mortalities ensued. However, no mortalities resulted in the Adonis extract group over a three month feeding period, and a noticeable pink coloration was observed in the skin of this group. Pathological examination of the fish fed the Adonis flower diet showed that the fish had an entreitis. The results of this experiment suggested the possible presence of toxic conpounds in $A$. aestivalis flower. However, the extract of $A$. aestivalis may serve as an excellent dietary pigment source.
\end{abstract}

The red coloration of salmonids and crustaceans has become of interest in the cultivation of these species as an important factor affecting consumer acceptance. The natural pink coloration of these species is mainly due to the carotenoid, astaxanthin $\left(3,3^{\prime}\right.$-dihydroxy- $\beta$, $\beta$-carotene$4,4^{\prime}$-dione). Salmonids cannot synthesize carotenoids thus it is necessary to feed carotenoids, especially astaxanthin, to obtain the desired pigmentation in intensive salmonid culture.

A number of studies have indicated that crustacean meal and its lipid extract could be used as dietary pigment source for salmonid culture. ${ }^{1-3)}$ However, there are several problems related to the utilization of crustacean waste materials as dietary ingredients (e.g. high mineral content and poor digestibility) without extensive processing to improve their dietary quality." Moreover, the technological drying of crustaceans or crustacean processing wastes involves a considerable loss of carotenoid pigment. ${ }^{\text {.) }}$

Other investigators have studied the possible use of plants as sources of distary pigments, paprika and marigold ${ }^{\mathrm{s})}$; marigold and squash flower $^{8)}$; chestnut flower ${ }^{7)}$; Hyppophea rhamnoides oil. ${ }^{8)}$ However, the feeding of plant pigment sources often produced undesirable yellowish coloration due to the lack of red xanthophylls.

Nakazoe and $\mathrm{Hata}^{*}$ reported that the green algae Haematococcus pluvialis could be a good astaxanthin source for sea bream. However, they also noted that the direct use of $\boldsymbol{H}$. pluvialis as a dietary pigment source had limited effect on pigmentation. The red yeast Phaffia rhodozyma was found to contain astaxanthin as a major pigment. ${ }^{*}$ Johnson et al. ${ }^{10)}$ studied the possibility of this yeast as a dietary pigment source for salmonids and crustaceans. They concluded that this yeast was an excellent astaxanthin source for salmonids and lobster, if the cell walls of yeast were ruptured prior to use.

It was well established that certain species of Adonis flower such as $A$. annua ${ }^{11,12)}$ and $A$. aestivali $^{13)}$ contained astaxanthin as a major pigment. According to Neamtu et al., ${ }^{13)}$ more

*1 Department of Food Science and Nutrition, University of Rhode Island, Kingston, RI 02881, U.S.A.

*2 Present Address: Department of Home Econmics, Kagoshima Prefectural Junior College, Shimoishiki,

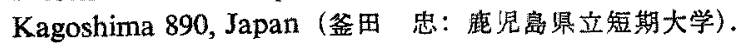

* Department of Biochemistry, Institute of Agronomy, Cluj-Napoca, Rumania.

*4 Laboratory of Marine Biochemistry, Faculty of Fisheries, Kagoshima University, Shimoarata, Kago-

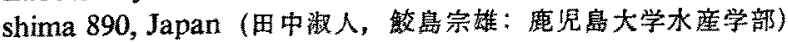

* J. Nakazoe and M. Hata: Abstract of the Jap. Soc. Sci. Fish. 53rd Annual Conference, 1978, p. 27. 
than $80 \%$ of the total pigments in $A$. aestivalis was astaxanthin, mostly in the ester form. Their results suggested that this fiower could be used for salmonids as a pigment source. Brinchmann ${ }^{182}$ noted the possible presence of alkaloids and some toxic compounds such as cardiac glycosides in $A$. aestivalis and $A$. annua. There are no reports on the feeding of Adonis flower to fish.

The present study was conducted to determine whether $A$. aestivalis could be used as a dietary pigment source for salmonids.

\section{Materials and Methods}

\section{Fish Culture}

Two sizes of rainbow trout (average weight of $100 \mathrm{~g}$ and $400 \mathrm{~g}$ ) were purchased from American Fish Culture, Carolina, Rhode Island, U. S. A. In experiment I, thirty of the larger sizes flsh were divided into two groups, a control and test group which were fed the pigment extract of $A$. aestivalis (Adonis extract). In experiment II, sixty smaller fish were divided into three groups, a control, Adonis extract and a group fed the Adonis flower. Each group was held in a 470 liter fiber glass fish tanks. The culture tanks were operated according to Kuo et al. ${ }^{1}$ and Kamata*: water temperature was maintained at $12-12.5^{\circ} \mathrm{C}$, oxygen level $8.0 \pm 0.3 \mathrm{ppm}, \mathrm{pH} 6.3 \pm$ 0.2 and water rate $7.5 \mathrm{l} / \mathrm{min}$. The larger fish groups were fed at a rate of $2 \%$ of their body weight a day for eight weeks. The smaller fish were fed $3 \%$ of their body weight for three months.

The carotenoid composition in the petals of the flower A. aestivalis is presented in Table 1.

\section{Preparation of Fish Diets}

Control diet: The Oregon test diet for rainbow trout $^{17)}$ was modified and used as a control diet. The formula of the diet is shown in Table 2, pellets were formulated according to Kuo et al. ${ }^{1)}$ and Kamata.*

Adonis extract diet: The carotenoids were extracted from $A$. aestivalis with acetone in a Waring blender. After the pigments were transferred into petroleum ether (PE), PE was completely removed from the extracts by use of a rotary evaporator followed by storage in a desiccator under vacuum overnight. The pigments were then dissolved in cod liver oil and
Table 1. Carotenoid composition in flower petal of Adonis aestivalis

\begin{tabular}{lrr}
\hline \multicolumn{1}{c}{ Carotenoids } & $\mu \mathrm{g} / \mathrm{g}$ & \multicolumn{1}{c}{$\%$} \\
\hline B-Carotene & 16.43 & 0.83 \\
4-Hydroxyechinenone & 17.62 & 0.89 \\
3-Hydroxyechinenone & 33.26 & 1.68 \\
Astaxanthin diester & 1525.07 & 77.02 \\
Lutein & 122.37 & 6.18 \\
Adonixanthin & 104.35 & 5.27 \\
Astaxanthin & 66.53 & 3.36 \\
Unknown & 61.78 & 3.12 \\
3,3',4,4'-Tetrahydroxy- & 32.47 & 1.64 \\
\hline B-carotene & 1979.88 & 99.99 \\
\hline Total carotenoid & & \\
\hline
\end{tabular}

Table 2. Composition of diets

\begin{tabular}{lccc}
\hline \multicolumn{1}{c}{ Ingredients } & Control & $\begin{array}{c}\text { Adonis } \\
\text { Flower }\end{array}$ & $\begin{array}{c}\text { Adonis } \\
\text { Extract }\end{array}$ \\
\hline $\begin{array}{l}\text { Casein (Vitamin } \\
\text { free) }\end{array}$ & 30.68 & 30.68 & 30.68 \\
Gelatin & 1.95 & 1.95 & 1.95 \\
Dextrin & 6.5 & 6.5 & 6.5 \\
Carboxymethyl & 0.845 & 0.845 & 0.845 \\
$\quad$ Cellulose & & & \\
Mineral Mix*1 & 2.6 & 2.6 & 2.6 \\
Vitamin Mix & 1.3 & 1.3 & 1.3 \\
Cod Liver Oil*3 & 9.75 & 9.75 & 9.75 \\
Vitamin E & 0.39 & 0.39 & 0.39 \\
$\quad$ (250 IU/g) & & & \\
Cholin chloride & 0.65 & 0.65 & 0.65 \\
CaCO & 0.585 & 0.585 & 0.585 \\
Alphacel & 8.99 & 3.94 & 8.98 \\
Adonis Flower & - & 5.05 & - \\
Adonis Extract & - & - & 0.01 \\
L-Arginine-HCl & 0.76 & 0.76 & 0.76 \\
Squid Extract & 35.0 & 35.0 & 35.0 \\
\hline & 100.000 & 100.000 & 100.000 \\
\hline
\end{tabular}

* 1 Berrnart-Tomarelli modified salt mixture.

*2 $\quad 0.02 \%$ Ethoxyquin was added.

mixed with other diet ingredients. The final concentration of carotenoids in the diet was $10 \mathrm{mg} / 100 \mathrm{~g}$ diet.

Adonis flower diet: The petals of the flower were ground in a blender and mixed with other feed ingredients. The final carotenoid concentration in the diet was $10 \mathrm{mg} / 100 \mathrm{~g}$ diet. The amino acid profiles of both test and control diets were analyzed to determine if the diets supplied all essential amino acids in sfficient levels. According to the amno acid profiles, the level of arginine was low compared according to the amino acid requirements for chinook

* T. Kamata; The pigmentation of rainbow trout, Salmo gairdneri, Master's Thesis, University of Rhode Island, Kingston, R.I., U.S.A. 1977, pp. 36-37. 
salmon. ${ }^{163}$ The diets were reformulated with supplemental arginine (L-arginine $\cdot \mathrm{HCl}$ ) added (Table 2).

\section{Carotenoid Analysis}

At the end of feeding study, the rainbow trout were sacrificed. The skin and fins were carefully separated from the flesh. The pigments were separately extracted from the skin and the flesh with acetone in a Waring blender. With the larger fish (Experiment I), male and female fish were separately analyzed and the analysis of carotenoids of each group was made in duplicate. In Experiment I, a pool of three fish was used for each analysis and in Experiment II, $6-7$ fish were used. After extraction, the pigment extract was transferred into $\mathrm{PE}$ by the addition of water and concentrated to a small volume on a rotary evaporator. The caroteniods were first separated on a Microcel-C column using 1-4\% acetone in $\mathrm{PE}$ as a developing solvent. Each pigment fraction was then saponified with $10 \% \mathrm{KOH}$ in methanol under nitrogen at room temperature overnight. After saponification was comleted, the pigments were re-extracted with a mixture of $\mathrm{PE}$ and ethyl ether. For astacene, formed from astaxanthin and its esters by saponification, a small amount of acetic acid was used to bring it to the epiphase. A $\mathrm{MgO}$ : Hyflo Supercel $=1: 2$ column and Silicagel$G$ thin layer chromatography plate were used for further separation and purification of pigments. The purified carotenoids were identified based on their visible absorption spectra, $\mathrm{Rf}$ values on TLC plate before and after saponification, and chemical tests such as acetylation, methylation and reduction. ${ }^{17)}$ Co-chromatography with authentic standards was also employed for the identification of carotenoids. For the quantitative determination, $E_{1 \mathrm{~cm}}^{1 \%}$ values of 2500 and 2000 were used for lutein and astaxanthin, respectively. ${ }^{18)}$

\section{Pathological Examination}

Pathological examination of the fish fed Adonis extract and Adonis flower diets were conducted by Dr. Wolke of the Department of Fisheries, Aquaculture and Pathology, the University of Rhode Island, Kingston, Rhode Island.

\section{Results and Discussion}

\section{Experiment}

The larger fish were fed the controled diet and Adonis extract for eight weeks. At the end of a feeding study, the test fish, particularly the males, exhibited a bright red pigmentation in the skin and fins. The fermales showed less pigmentation in the skin and fins than the males. However, the females had more red coloration in the fiesh than did the males. The controled male fish were also obsreved to have a slight pink coloration in the skin but no pigmentation was observed in the flesh. The controled female had no red coloration in the skin nor in the flesh.

The carotenoid composition of the fish are presented in Table 3. In both male and female fish, lutein and sataxanthin diester were found to be major pigments in the skin followed by astaxanthin mono ester and free astaxanthin. Free astaxanthin was found to be the predominant

Table 3. Carotenoid composition of the fish fed with Adonis aestivalis extract for eight weeks $(\mu \mathrm{g} / \mathrm{g}$ wet basis)

\begin{tabular}{|c|c|c|c|c|c|c|c|c|c|c|}
\hline \multirow{3}{*}{ Carotenoids } & \multicolumn{5}{|c|}{ Control } & \multicolumn{5}{|c|}{ Adonis Extract } \\
\hline & \multicolumn{2}{|c|}{ Male } & \multicolumn{3}{|c|}{ Female } & \multicolumn{2}{|c|}{ Male } & \multicolumn{3}{|c|}{ Female } \\
\hline & Skin & Flesh & Skin & Flesh & Egg & Skin & Flesh & Skin & Flesh & Egg \\
\hline Lutein & 0.90 & 0.01 & 1.05 & 0.08 & 0.17 & 2.50 & 0.04 & 1.52 & 0.36 & 2.44 \\
\hline Unknown & - & - & - & - & - & 0.05 & - & 0.03 & - & 0.05 \\
\hline Zeaxanthin & - & - & - & - & - & 0.13 & trace & - & - & - \\
\hline Adonixanthin & - & - & - & - & - & trace & 0.1 & trace & 0.03 & - \\
\hline Astaxanthin diester & 0.42 & - & - & - & - & 1.32 & - & 1.03 & - & - \\
\hline Astaxanthin monoester & 0.10 & - & - & - & - & 0.57 & - & 0.33 & - & - \\
\hline Astaxanthin & 0.01 & - & - & - & - & 0.44 & 0.70 & 0.19 & 1.17 & 3.11 \\
\hline Total Astaxanthin & 0.53 & - & - & - & - & 2.33 & 0.70 & 1.55 & 1.17 & 3.11 \\
\hline Total Carotenoids & 1.43 & 0.01 & 1.05 & 0.08 & 0.17 & 5.01 & 0.75 & 3.10 & 1.56 & 5.60 \\
\hline
\end{tabular}

Each value is indicated as mean of two analyses and three fish were used for each analysis. 
pigment in the flesh. In the control fish, a small amount of astaxanthin esters and free astaxanthin $(0.53 \mu \mathrm{g} / \mathrm{g})$ was detected in the skin of the male. However, only lutein was isolated from the skin and fiesh of the females and the fiesh of the males. The higher levels of astaxanthin in the test fish clearly indicated that the fish incorporated this pigment from the diet.

There were differences in the distribution of carotenoids between the male and female test fish. In the males, the concentration of the total astaxanthin (astaxanthin di- and monoester and free astaxanthin) was greater in the skin $(2.33 \mu \mathrm{g} / \mathrm{g})$ than the total astaxanthin in the flesh $(0.7 \mu \mathrm{g} / \mathrm{g})$. However, it was found that the total astaxanthin of the skin $(1.55 \mu \mathrm{g} / \mathrm{g})$ was only slightly higher than that of the flesh $(1.77 \mu \mathrm{g} / \mathrm{g})$ in the female. The combined total astaxanthin levels (skin and flesh) of the male and female fish were similar $(3.03 \mu \mathrm{g} / \mathrm{g}$ and $2.72 \mu \mathrm{g} / \mathrm{g}$, respectively). The highest astaxanthin content was found in the eggs of the test fish $(3.11 \mu \mathrm{g} / \mathrm{g})$.

The finding of the differences in distribution of astaxanthin between the male and female fish and the high astaxanthin content in the eggs was thought to be related to the degree of maturation of the fish. It is well documented that carotenoids are transported to the skin in males and to the eggs in females during the development of the gonads. ${ }^{19)}$ Crozier $^{20)}$ reported that the spawning male fish stored more than $95 \%$ of total pigment in the skin while $85 \%$ of total pigments were deposited in the eggs in the females. $\mathrm{He}$ also stated that the pigments in the skin were predominantly the ester forms while the pigments present in the eggs were the free forms. The results shown in Table 3 suggests that astaxanthin was transported and deposited in the skin as a ester in the male while the pigments were transported to the eggs as a free form in the female.

\section{Experiment II}

In Experiment II, the smaller sized fish were used. They were fed the Adonis extract diet and the Adonis flower diet. It was observed that Adonis flower group showed a greatly reduced intake of the diet after two weeks of feeding. A slight off-odor was noticed in the Adonis fiower diet 5-6 days after the preparation of the diet even though the diet was stored in the refrigerator. This odor was not noted in the Adonis extract or the control diet. Although the cause of the off-odor was unhnown, it was thought to be one of the reasons why the fish refused the Adonis flower diet. After the second week of feeding, the first mortality was observed in the Adonis flower group. Subsequently, a continuous increase in mortalities resulted in the Adonis flower group. At the end of one month, the mortalities in the Adonis flower group exceeded $30 \%$. Due to this high mortality, the feeding study of the Adonis flower was discontinued and the fish were submitted to pathological examination. No mortalities occurred in either the Adonis extract or the control group, and the feeding study of Adonis extract was continued for two more months. During the three months of feeding the Adonis extract diet, no mortalities were recorded and the growth rate of this group was similar to the control group. It appeared

Table 4. Carotenoid composition of the fish fed Adonis aestivalis flower and Adonis aestivalis extract for one and three months $(\mu \mathrm{g} / \mathrm{g}$ wet basis)

\begin{tabular}{|c|c|c|c|c|c|c|c|c|c|c|}
\hline & \multicolumn{4}{|c|}{ Control } & \multirow{2}{*}{\multicolumn{2}{|c|}{ Adonis }} & \multirow{2}{*}{\multicolumn{2}{|c|}{$\frac{\text { Extract }}{\text { Flesh }}$}} & \multirow{3}{*}{$\begin{array}{c}\text { Adonis } \\
\text { Skin } \\
1\end{array}$} & \multirow{3}{*}{$\begin{array}{c}\text { Flower*1 } \\
\text { Flesh } \\
1\end{array}$} \\
\hline & \multicolumn{2}{|c|}{ Skin } & \multicolumn{2}{|c|}{ Flesh } & & & & & & \\
\hline & $1^{* 2}$ & $3 * 3$ & 1 & 3 & 1 & 3 & 1 & 3 & & \\
\hline Lutein & 0.26 & 0.34 & 1.05 & 0.07 & 0.36 & 0.55 & 0.17 & 0.40 & 0.56 & 0.16 \\
\hline Zeaxanthin & - & - & - & - & trace & 0.11 & - & - & trace & - \\
\hline Unknown & - & - & - & - & - & 0.01 & - & - & - & - \\
\hline Astaxanthin diester & - & - & - & - & 1.06 & 1.81 & - & 一 & 0.05 & - \\
\hline Astaxanthin monoester & - & - & - & - & 0.40 & 0.47 & - & - & trace & - \\
\hline Astaxanthin & - & - & - & - & 0.43 & 0.47 & 0.45 & 0.71 & trace & trace \\
\hline Total Astaxanthin & & & & & 1.89 & 2.75 & 0.45 & 0.71 & 0.05 & trace \\
\hline Total Carotenoids & 0.26 & 0.34 & 0.05 & 0.07 & 2.25 & 3.42 & 0.62 & 1.11 & 0.61 & 0.16 \\
\hline
\end{tabular}


that over the feeding period tested, the Adonis extract was nontoxic to rainbow trout and did not affect the nutritional value of the diet.

The carotenoid comosition of the fish fed the Adonis extract and the Adonis flower were analzed (Table 4). The fish fed the Adonis extract diet showed a pink coloration in the skin and fins but not in the flesh. However, a red pigmentation was observed in the skin, fins and in the flesh after three months. The fish fed the Adonis flower and the control diets showed no pigmentation. At the end of the one moth feeding, the total astaxanthin content in the skin and the flesh of the fish fed the extract was $1.89 \mu \mathrm{g} / \mathrm{g}$ and $0.45 \mu \mathrm{g} / \mathrm{g}$, respectively. After three months the pigment content increased to $2.75 \mu \mathrm{g} / \mathrm{g}$ and $0.71 \mu \mathrm{g} / \mathrm{g}$, respectively. These results indicated that the skin and fins were the sites of pigment deposition. The higher pigment content in the skin than the flesh in the rainbow trout was also erported by Hata and Hata. ${ }^{21}$ Although the red coloration was not observed visually in the fish fed the Adonis flower, a small amount of astaxanthin was incorporated in the skin as esters $(0.05 \mu \mathrm{g} / \mathrm{g})$ (Table 4$)$.

According to the pathological examination of fish conducted by Dr. Wolke, it was observed that the fish fed the Adonis flower had an enlarged gall bladder and were found to have necrotic cells in the intestine along with migrating white blood cells. However, no significant lesions were found in other organs. In the Adonis extract and the control groups, there were no significant lesions detected in any of the organs examined, although a slightly fatty liver was observed in the control fish. Enteritis was also detected in the fish fed the Adonis flower. This probably related to the high incidence of mortality observed in this group. However, the exact cause of the enteritis was not determined.

A number of investigators have reported that Adonis spp. contained toxic cardiac glycosides. The possible toxicity of $A$. annua and $A$. aestivalis to trout was suggested by Brinchmann. ${ }^{14)} \mathrm{He}$ mentioned that alkaloids and other toxic compounds may be present, especiall cardiac glycosides. The presence of alkaloids in $A$. aestivalis is not established. However, various cardiac glycosides were isolated from several species of Adonis flowers. Sanatvy and Reichstein"2) isolated cymarin from $A$. amurenis as the major active cardiac glycoside. Aside from cymarin, adonitoxin was also found in $A$. vernalis. ${ }^{23)}$
Kavalali ${ }^{23)}$ analyzed $A$. aestivalis and isolated the cardiac glycoside, cymarin. The toxic effect of these compounds to fish has not been reported. However, toxicity of Adonis spp. to such domestic animals as sheep ${ }^{25)}$ have been reported. According to his study, $A$. annua is lethal to sheep at about $1 \%$ of the subject's weight of plant. ${ }^{25}$ )

Although the actual reason for enteritis found in the fish fed the Adonis flower was not determined, the presence of cardiac glycosides was likely the cause. It is known that the cardiac glycosides are water soluble and they are not extracted from materials with acetone. This should explain why the mortality occurred in only the fish fed the Adonis flower diet and no mortality resulted in the fish fed the Adonis extract diet.

The results of this experiment suggested that the direct use of $A$. aestivalis as a dietary pigment source would reduce production of fish probably because of the presence of some toxic compounds such as cardiac glycosides. The pigment extracts of $A$. aestivalis could be one of the best dietary pigment sources for trout because of the high concentration of astaxanthin.

\section{Acknowledgements}

We thank Dr. Richard E. Wolke, Department of Fisheries, Aquaculture, Pathology, University of Rhode Island, Kingston, R. I., for pathological examination of the fish.

This study was supported in part by NOAA Office of Sea Grant, U.S. Department of Commerce under Grant Number NA-79AA-D-00096. Rhode Island Agricultural Experiment Station Contribution Number 2514.

\section{References}

1) H-C. Kuo, T-C. Lee, T. Katayama, and K. L. Simpson: Alimenta, 15, 47-51 (1976).

2) J. Spinelli, L. Lehman, and D. Wieg: J. Fish. Res. Bd. Canada, 31, 1025-1029 (1974).

3) J. Spinelli and C. Mahnken: Aquaculture, 13, 213-223 (1978).

4) S. Meyers: Feedstiffs, May, 9, 26-27 (1977).

5) D. H. Peterson, H. K. Jager, G. M. Savage, G. N. Washburn, and $\mathrm{H}$. Werters: Trans. Am. Fish Soc., 95, 408-414 (1966).

6) R. G. Lee, G. G. Neamtu, T-C. Lee, and K. L. Simpson: Rev. roum. Biochem., 15, 287-293 (1978).

7) G. G. Neamtu, C. M. Weaver, R. E. Wolke, and K. L. Simpson: Rev, roum. Biochem., 13, 25-30 
(1976).

8) T. Kamata, G. G. Neamtu, and K. L. Simpson: Rev. roum. Biochem., 14, 253-258 (1977).

9) A. G. Andrewes and H. P. Starr: Phytochem., 15, 1009-1011 (1976).

10) E. A. Johnson, T. G. Villa, and M. J. Lewis: Aquaculture, 20, 123-134 (1980).

11) A. Seybold and T. W. Goodwin: Nature, 184, 1714-1715 (1958).

12) K. Eggar: Phytochem., 4, 609-618 (1965).

13) G. G. Neamtu, V. Tamas, and C. Bodea: Rev. roum. Biochem., 3, 305-310 (1966).

14) H.J. Brinchmann: in "Pigmentation of pondreard fish" (translated by P. M. Jangaard), Technical University of Norway (1967), pp. 1-39.

15) D. J. Lee, J. N. Roehn, T. C. Yu, and R. O. Sinnhuber: J. Fish. Res. Bd. Canada, 34, 24172421 (1967).

16) E. T. Mertz: in "Fish in Research" (ed. by $O$. W. Neuhaus and J. E. Halver), Academic Press,
New York, 1969, pp. 233-244.

17) B. H. Davies: in "Chemistry and Biochemistry of Plant Pigments. Vol. II" (ed. by T. W. Goodwin), Academic Press, New York, 1969, pp. 38165.

18) D. B. Rodriguez, K. L. Simpson, and C. O. Chichester: Int. J. Biochem., 4, 213-222 (1973).

19) T. W. Goodwin: Biol. Rev. Cambridge, 25, 391-413 (1950).

20) G. F. Crozier: J. Fish. Res. Bd. Canda, 27, 973-975 (1970).

21) M. Hata and M. Hata: Tohoku J. Agric. Res., 26, 35-40 (1975).

22) F. Sanatvy and T. Reichstein: Pham. Acta Helv., 23, 153-188 (1947).

23) A. Katz and T. Reichstein: Pham. Acta. Helv., 22, 437-459 (1947).

24) G, Kavalali: Illoydia, 36, 426 (1973).

25) A. Degen: Fortschritte der Landwirtschaft, 7, 556 (1932). 